\title{
'Man Hunt Intimacy: Man Clean Bathroom': Women, Sexual Pleasure, Gender Violence and HIV
}

\section{Alice Welbourn}

\section{Introduction}

'The more men participated in the care of children, housework and daily conversation ... the more the wife increased her level of satisfaction and sexual intimacy.' A recent light-hearted article in the International Herald Tribune finished with these supposedly surprising findings, based on a survey of 21,000 Americans conducted by the US Bureau of Labor Statistics (McNeil 2004). But what this US news report did not spell out was how men's contribution - or lack of it - to household tasks and expenditure and the daily burden of running a home is also closely linked not only to sexual intimacy and pleasure, but also to sexual dissatisfaction, gender violence and HIV. Women around the world have known for many years what this survey has now established as 'fact' in the USA. But as usual, women's stories from elsewhere in the world have gone unnoticed.

\section{Sex, work and money}

In Northern Sierra Leone in 1991, I conducted a seasonal calendar exercise separately with men and with women in one community (Welbourn 1991). Both groups explained clearly how, during the 'hungry season' - the lean months when the grain store is empty, when it is wet and cold, when there is heavy work to be done (mainly by the women), such as weeding the fields, and before the new crop has been harvested - everyone finds life miserable and quarrels erupt, men beat their wives, people have to 'eat credit' and children go hungry. The women described how heavy work 'brings the sickness'. This story has been repeated many times elsewhere: in Ghana for instance, a similar drawing exercise revealed how patterns of men and women having extramarital affairs, and the incidence of increased sexually transmitted infections (STIs) and pregnancy coincided, in the respondents' views, with times of famine and cold, heavy workload, money shortage and quarrels in the home. ${ }^{1}$

In rural Uganda too, women described to me in 1991 how tough they found it living with their husbands without any support for all their household tasks or expenditure: but they said that they could not contemplate leaving their husbands because they would fear for what would happen to their children if they were left in the home without a mother. In Zambia also, in 1997, another study reports: 'the domestic tensions caused by alcohol consumption, quarrels over finances and, most often, quarrels over sex (demanded by men and refused by exhausted women ... "when we are tired and refuse to have sex with our husbands, we are asked to sleep on the floor')' (Smith and Howson 2002: 147) (Figure 1).

This same study reported that:

Sexual violence, highlighted as a problem only by women (older and younger), was not considered in the same way by men. Physical violence also featured, particularly within the domestic context, identified as a grievance by women and as a right by men. Younger men from Zimbabue reported that they felt it was appropriate to beat their wives if they found them sleeping in the fields, because they believed the women were lazy. (Smith and Howson 2002: 147).

Such stories are universal, as the survey from the USA illustrates, and women in all parts of the world connect with them. They reflect common experiences with men's behaviour in most societies of the world, thanks to the way in which most men in these societies are expected to conform to certain 
Figure 1 ' $W$ hen we are tired and refuse to have sex with our husbands, we are asked to sleep on the floor, under the bed' (Older women's group, Zambia)
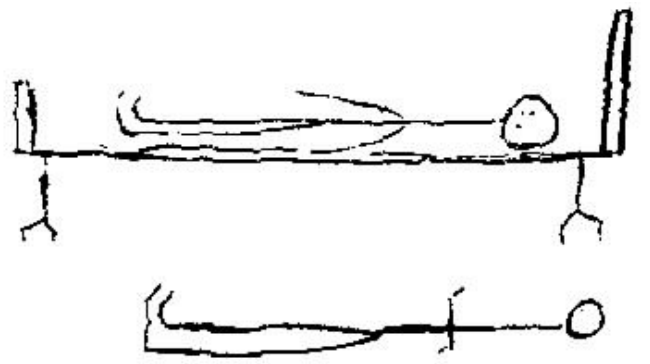

'male norms'. 2 Sadly many of us know only too well that hot on the heels of these quarrels, physical violence and their consequences come vulnerability to STIs and HIV, as men seek comfort by having sex with other women who may have less justification for arguing with them, and as their wives also turn to other men for sex in order to buy school clothes for their children or food for the daily meal. In many parts of the world, women are brought up by older female relatives to expect to need to have sex with men other than their husbands to make ends meet and, as long as it is not totally obvious, men often turn a blind eye to this, since they are doing the same thing themselves with other women. Work, money, sex and violence are inextricably interrelated and women believe otherwise at their peril.

\section{Breaking the cycle}

The situations described above show how vulnerable women are to contracting HIV. But is HIV inevitable? It is clear that girls' education and the prospect of independent income through getting that education is the important thing which can break the cycle of women's dependency. ${ }^{3}$ Good sex education for boys and girls too, as well as laws which ensure equitable property, inheritance and child custody rights for women are clearly also important factors. But for women who are already past school age, is there no means of breaking out of this cycle of economic dependency and physical, sexual and psychological violence once it has begun? Fortunately there are some community-based programmes that have managed to break through this negative vicious cycle.

Once people understand these links, and how much everyone suffers because of them - men as well as women and children - they can then start to do something about them. $A$ recent initiative by an $\mathrm{NGO}$ in Southern Africa that has male staff members who work a long way from home was a training programme for the staff. The male staff realised that they only send a proportion of their salaries home each month, since they expect their wives to make ends meet by having sex with other men in their absence. They resolved in future to send more money home and to see if their NGO could support their wives and children to live closer to them. ${ }^{4}$ In another recent workshop in Latin America, an exercise explored the meaning of the word 'love' and what the participants expect from their partners when they use that word, compared with what their partners get from them in return (PLAN International et al. 2005). ${ }^{5}$ One honest young male participant, a youth worker, announced after this exercise that it had helped him to re-evaluate his own relationship in the light of the discussion, and had made him realise that he demanded more of his partner in many respects than he gave.

In the same workshop, a female group of doctors, sex workers, HIV-positive women and NGO staff worked together around an outline drawing of a woman's body on the ground, discussing and sharing together what gave them pleasure and what turned them off when having sex. The same women went on to role play and share different scenarios from their own or from friends' lives. These included a woman having to cope with sexual harassment from her male boss at work and trying to decide whether she could afford to leave that job or not; another woman being expected to stay at home and look after the children all the time outside work hours; and a sex worker having to negotiate carefully with a pimp so that he would not beat her for not having brought him enough money from her earnings. Workshops such as these which facilitate participants to share and compare their experiences in a non-judgemental, caring and very practical way enable people to recognise these linkages in their lives, become less judgemental and more understanding of others' life experiences, and start to be open to possibilities for change.

Workshops elsewhere have taken these ideas even further. In the Gambia, for instance, men have learnt the importance of the female orgasm and the G-spot and now recognise that the 'wham, bang thank you ma'am' approach to sex leaves women emotionally and sexually unsatisfied (Shaw 1998). 
They have also learnt that physical violence is wrong and that it has far-reaching physical and emotional effects, not just on the woman but on the children, the men themselves, and in the wider community. Condom use has also been introduced to protect against infertility. In the Gambia (and Uganda and elsewhere) community participants in separate peer groups have learnt how a condom works and practised putting it on a banana.

\section{Learning for change}

Participants in these workshops have been able to take home new knowledge about how their bodies work as well as those of their partners; they have been able to explore different ways of giving each other and asking for pleasure in their sex lives, safe in the knowledge that they will not be accused of having had an affair in order to learn such things, because everyone knows that these are issues which all the workshop participants are addressing and learning about together. They have learnt that condom use in sex is not only possible but can also become a part of sexual foreplay, that nonpenetrative sex can be as pleasurable as penetrative sex, that having sex safe in the knowledge that you will not get pregnant or catch - or transmit - an STI can actually enable a woman to enjoy sex much more than she had before. In addition the women now know that having sex with a man who is ready to help her with household tasks and expenditure, discuss issues and share decisions with her, and develop a relationship based on mutual respect, is not only far more pleasurable for the woman, but also makes life much easier and happier for the man and the whole family. These and other revelations through such workshops have been reported widely in many countries. This shows then, that the cycle of violence can and has been reversed in these communities.

Such workshops and exercises are not always easy: people who have been sexually abused as children, or who have been raped, or who are stuck in abusive relationships, or who have to sell their bodies for sex, often find that strong painful memories and emotions are raised to the surface. Even something as simple as encouraging people to remember a good time in their childhood, or asking them what they look for in someone they love can raise deep emotions. So such workshops have to be well run by trained facilitators with caution and care. Like any strong medicine, there can be unwelcome sideeffects, so the workshop exercises must be handled with respect.

\section{Sexuality matters}

What about HIV-positive women in all this? HIVpositive women - and men and transgendered people - have the right to happy, healthy and safer sex in their lives just as much as anyone else. We also have the right to have children, if we want to, and when we want to. We are all of us sexual beings, no matter who we are. (Almost) none of us would be here if it hadn't been for our parents having sex. Our sexuality is a central part of all our lives, along with our physical and psychological make-up. As Hanne Ris $\varnothing r$ of the Danish Family Planning Association (FPA) pointed out many years ago to her patients in her regular general practice surgery, we do ourselves a lot of damage if we deny that our sexuality exists. For those of us who maybe had no opportunity to learn about the far-reaching importance of good sex in our lives before our diagnosis, such workshops can also give us the opportunity and skills to reclaim our own bodies from the clutches of an HIV diagnosis; to learn about what gives us pleasure and to develop a closer, more loving, mutually respectful and satisfying relationship with those with whom we choose to have sex, in the knowledge that they are likely to realise through these workshops that respect for us means that their lives become more meaningful too.

'Man hunt intimacy: man clean bathroom'. Now there's a thought. 


\section{Notes}

1 Gill Gordon, with IPPF and Ghana FPA, 1991.

2 Important work by l'Associacion des Hombres contra la Violencia ( $\mathrm{AHV}$ ) in Nicaragua suggests that men's violence against women is a response to a fear that they may otherwise be regarded as gay by their peers, i.e. that male violence against women is a response to society-wide homophobia. The AHV works against both homophobia and gender violence across Nicaragua and beyond; see www.healthcomms.org/learn/learnO1.html

\section{References}

McNeil Jr, Donald G. (2004) 'Sorry Guys, Your Housework Lessons Aren't Over', International Herald Tribune, September

Oglethorpe, Judy and Gelman, Nancy (2004) HIV/AIDS and Conservation: Impacts and Ways to Reduce Them. Fact sheet for the Conservation Community, Washington DC: Africa Biodiversity Collaborative Group, www. frameweb.org/ ev.php?URL_ID=6786\&URL_DO=DO_TOPIC (accessed 14 July 2006)

PLAN International and local partners (2005) 'Paso a Paso', inaugural workshop for Latin America, Quito, Ecuador, May
3 However, caution also needs to be taken here, because schools can often be very dangerous places for girls, who can find themselves sexually exploited by teachers, older pupils, soldiers barracked nearby, etc.

4 Susan Amoaten pers. comm. See also Oglethorpe and Gelman (2004).

5 'Paso a Paso' inaugural workshop for Latin America (Paso a Paso is the Spanish translation of Stepping Stones, www.steppingstonesfeedback.org).

Shaw, M. (1998) Stepping Stones Gambia Adaptation, Banjul: MRC/ActionAid

Smith, Ann and Howson, John (2002) 'Safely Through the Night: A Review of Behaviour Change in the Context of HIV/AIDS in Africa', in A. Cornwall and A. Welbourn (eds), Realizing Rights: Transforming Approaches to Sexual and Reproductive Well-being, London: Zed Books: 141-53

Welbourn, Alice (1991) The Social and Economic Dimensions of Poverty and III-Health, report based on fieldwork in Sierra Leone, Uganda and Ghana and relevant literature, January, London: Department of International Community Health, Liverpool School of Tropical Medicine 